\title{
Rede Neural Artificial Aplicada ao Rastreamento de Pontos de Máxima Potência de Painéis Fotovoltaicos com Sombreamento Parcial
}

\author{
Gasperacco, W.; Rocha, T.S.; Mazzoco, G.; Fardin, J. F.; Simonetti, D.S. L. \\ Programa de Pós-Graduação em Engenharia Elétrica, Universidade Federal do Espírito Santo, Vitória, ES, Brasil.
}

* e-mail: wellington.gasperacco@ifes.edu.br

\begin{abstract}
Resumo
Nos painéis fotovoltaicos, o ponto de potência máxima depende dos níveis de irradiância solar e temperatura. Determinar o valor de potência máxima é uma tarefa complexa, em especial, quando a irradiância não é uniforme, isto é, quando há sombreamento parcial no painel. Este trabalho aplica uma rede neural artificial (RNA) para identificação do ponto de operação com potência máxima em painéis fotovoltaicos em diferentes condições de sombreamento, seja ele total ou parcial. Utiliza-se como parâmetros de entrada no treinamento e teste da RNA a irradiância solar (dada em W / $\mathrm{m}^{2}$ ), temperatura $\left({ }^{\circ} \mathrm{C}\right)$ e a tensão de circuito aberto do painel $(\mathrm{V})$. A informação buscada na saída da rede neural artificial é o valor de tensão (V) a impor para operar em máxima potência. No estudo, por simulação, foi desenvolvida uma RNA do tipo MLP (Perceptron de Múltiplas Camadas) com duas camadas ocultas de 13 neurônios cada. Foram utilizadas 554 amostras de parâmetros para o treinamento da RNA, e 92 para comprovação, gerados a partir de um modelo desenvolvido no software Matlab/Simulink ${ }^{\circledR}$. Os resultados dos testes retornaram uma taxa de erro em torno de $6 \%$, mostrando que a rede neural artificial com a abordagem proposta pode ser uma solução eficiente para detecção do ponto de máxima potência em diversas situações de sombreamento.
\end{abstract}

\begin{abstract}
In photovoltaic panels, the maximum power point depends on the levels of solar irradiance and temperature. Determining the maximum power value is a complex task, especially when the irradiance is not uniform, i.e. when there is partial shading on the panel. This work applies an artificial neural network (ANN) to identify the point of operation with maximum power in photovoltaic panels under different conditions of shading (solar radiation), total or partial. The solar irradiance (given in $\left.\mathrm{W} / \mathrm{m}^{2}\right)$, temperature $\left({ }^{\circ} \mathrm{C}\right.$ ) and the open circuit voltage of the panel $(\mathrm{V})$ are used as inputs for training and RNA testing. The information sought at the output of the artificial neural network is the voltage value (V) to be imposed to operate at maximum power. In the study, by simulation, an MLP (Multiple Layer Perceptron) type RNA was developed with two hidden layers of 13 neurons each. For ANN training were used 554 samples of parameters, and 92 for verification, generated from a model developed in Matlab / Simulink® software. The results of the tests returned an error rate around $6 \%$, showing that the artificial neural network with the proposed approach can be an efficient solution to detect the maximum power point in several shadowing situations.
\end{abstract}

Keywords (Palavras chaves): Artificial Neural Network, Solar Energy, MPPT, partial shading. 


\section{Encontro Científico de Física Aplicada}

\section{Introdução}

A demanda por energias renováveis vem se ampliando com o passar dos anos, trazendo inúmeros benefícios para o planeta, e a principal fonte de toda essa energia é o sol. A energia do sol é responsável por praticamente todas as formas de energia conhecidas, como a biomassa, hidráulica, eólica e fotovoltaica, esta última proveniente da utilização dos painéis fotovoltaicos. Painéis fotovoltaicos são mecanismos capazes de converter de forma direta a energia proveniente do sol em energia elétrica. Os painéis fotovoltaicos são compostos por células fotovoltaicas conectadas em série e/ou paralelo e em seus terminais surge uma diferença de potencial quando expostas à luz. Atualmente as células fotovoltaicas apresentam uma baixa eficiência, algo em torno de 16\% [1]. Uma forma de aumentar a eficiência dos sistemas de energia fotovoltaica é garantir que o painel opere em seu ponto de máxima potência instantânea, fazendo uso de técnicas denominadas MPPT (Maximum Power Point Tracking). Essas técnicas atuam de forma a alterar a resistência interna do painel fazendo que o mesmo opere no ponto onde a potência entregue pelo painel será a máxima possível na irradiância e temperatura existente [2].

Um dos principais problemas encontrados no rastreamento dos pontos de máxima potência é o sombreamento, ou seja, uma redução no valor da radiação solar, pois este muda as características da curva Tensão versus Corrente dos painéis fotovoltaicos. Esse valor da irradiação solar pode ser diferente em vários pontos do painel fotovoltaico, configurando o que se chama de sombreamento parcial. Em alguns casos o sombreamento pode ser inevitável podendo ser causado por folhas, sujidades em geral, depósito de neve, além do próprio movimento relativo do sol que muda durante o decorrer do ano. Além disso, quando uma célula se encontra sombreada, esta atua como uma carga, dissipando a corrente de entrada e criando os chamados pontos quentes. De forma a minimizar o efeito do sombreamento, são introduzidos os diodos de by-pass, que permitem a passagem da corrente sem danificar a célula, porém sem produzir potência no setor [3].

Em condições de sombreamento, arranjos série e/ou paralelo de painéis fotovoltaicos podem apresentar vários máximos locais em sua curva característica, mas apenas um deles é máximo global [4]. Como exemplo, a figura 1 mostra a curva característica, gerada por simulação, do painel fotovoltaico utilizado neste trabalho sem a presença do sombreamento e a figura 2 mostra a curva característica do mesmo sistema, mas com a presença de sombra na metade do painel.

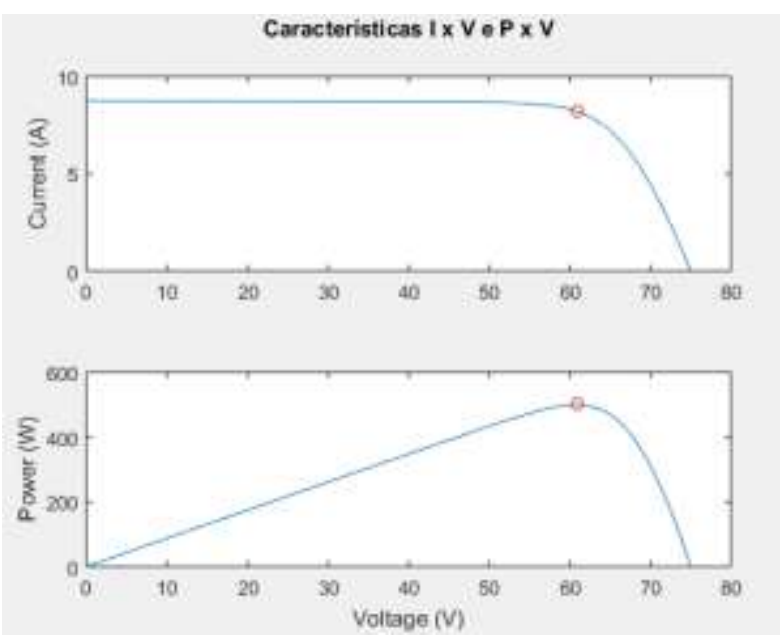

Figura 1: Painel fotovoltaico sem sombreamento, com radiação sola igual a $1000 \mathrm{~W} / \mathrm{m}^{2}$ e temperatura de operação igual a $25^{\circ} \mathrm{C}$.

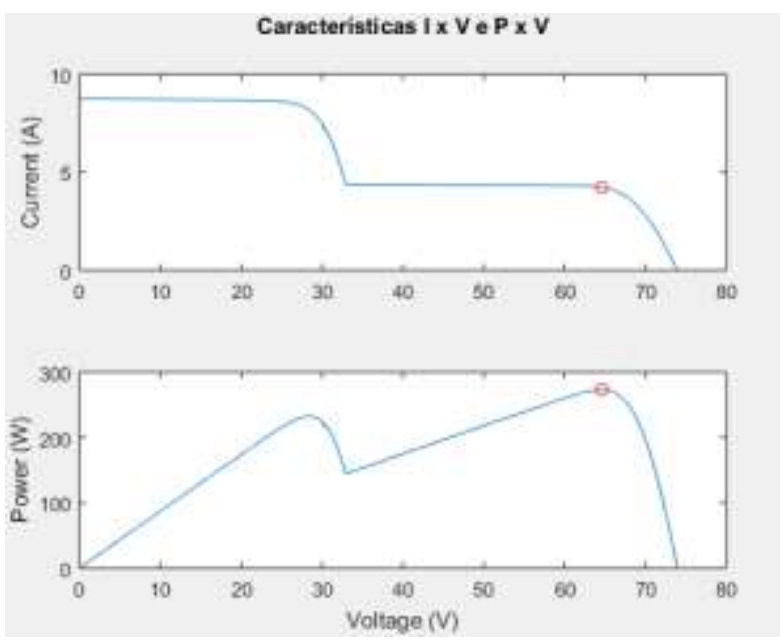

Figura 2: Painel fotovoltaico com sombreamento: metade do painel está com radiação solar igual a $1000 \mathrm{~W} / \mathrm{m}^{2}$ e outra metade com radiação solar igual a $500 \mathrm{~W} / \mathrm{m}^{2}$. Temperatura de operação igual a $25^{\circ} \mathrm{C}$.

Pode-se observar nas figuras a diferença do comportamento do ponto de máxima potência (que é exposta com um círculo vermelho na curva). Quando 
há o sombreamento, a curva característica potênciatensão pode possuir vários máximos locais. No nosso caso particular há dois pontos de máximos como pode ser observado na figura 2 (parte inferior). Isto dificulta o rastreamento do ponto de máxima potência por algumas técnicas convencionais. Por exemplo, no método Perturba e Observa, o valor da tensão de operação varia e é analisado se houve ou não aumento no valor da potência. Isto pode fazer com o sistema opere em um mínimo local, diminuindo a potência elétrica entregue pelo painel fotovoltaico. Em nossa opinião, a substituição dos algoritmos MPPT convencionais por uma rede neural, apresenta vantagem porque informa diretamente o ponto de máxima potência, pois as oscilações deixariam de existir, além de que o sistema convergiria quase que instantaneamente [1].

Assim, neste trabalho foi utilizado uma rede neural artificial com a finalidade de identificar o ponto de operação com potência máxima em painéis fotovoltaicos sob diferentes condições de sombreamento total e parcial.

\section{Materiais e métodos}

A Rede Neural Artificial (RNA) é uma técnica de inteligência artificial, inspirada no comportamento do neurônio biológico, isto é, as RNAs buscam reproduzir a fisiologia do neurônio humano [5]. Para a utilização desta técnica de inteligência computacional, nenhum conhecimento a priori das relações físicas entre as variáveis do sistema é necessário, sendo o único prérequisito a existência de uma base de dados, grande o suficiente para garantir o aprendizado da rede neural artificial contendo os valores de entrada e suas respectivas saídas, e que seja capaz de representar a dinâmica do processo em questão [6].

A Rede Neural Artificial utilizada para a geração desse artigo foi a Perceptron de Múltiplas Camadas (MLP), representada na figura 3 . A seleção dos parâmetros para essa arquitetura consiste basicamente na determinação do número de camadas da rede e do número de neurônios em cada camada.

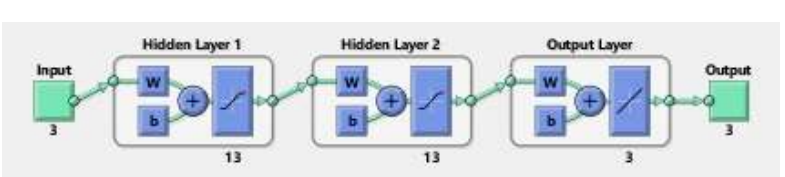

Figura 3: Rede Neural Artificial utilizada no trabalho.

O conjunto de dados de treinamento é basicamente formado por pares de entrada e saída, sendo caracterizada previamente a saída desejada para um determinado valor de entrada. O ajuste dos pesos (representado por w na figura 3 ) deve modificar o valor de saída obtida pela RNA de forma a minimizar o erro relativo à saída desejada. Entretanto, a simples minimização do erro para os padrões de treinamento pode não levar a valores satisfatórios. O objetivo dos algoritmos de treinamento de Redes Neurais Artificiais deve ser o de aproximar as funções geradoras dos dados, ou seja, gerar uma função matemática que represente o sistema e não simplesmente minimizar o erro do conjunto de dados de treinamento, em outras palavras, o objetivo do treinamento das redes neurais artificiais é obter uma rede que produza erros aceitáveis no conjunto de treinamento e que também responda apropriadamente a novos padrões de entrada. A regularização é um método que busca melhorar a capacidade de generalização dos algoritmos de aprendizado por meio de algumas restrições durante a fase de treinamento [7].

A técnica de treinamento supervisionado (quando se conhece as entradas e suas respectivas saídas) utilizada nesse trabalho é a Regularização Bayesiana. Esta técnica visa encontrar o equilíbrio entre o erro de treinamento e a magnitude dos pesos sinápticos, aumentando consideravelmente a capacidade de generalização da Rede Neural Artificial proposta. De um modo geral, o treinamento de RNAs tem como objetivo a redução do somatório dos erros quadráticos. Entretanto, a Regularização Bayesiana, acrescenta alguns parâmetros além do somatório dos erros quadráticos. Isso faz com que o treinamento com regularização dispense o uso de um conjunto de dados para validação para determinação do valor ótimo dos parâmetros de regularização [7]. 
Para a montagem da base de dados necessária para o treinamento e testes da RNA, foi desenvolvida uma plataforma utilizando o software MatLab/Simulink®. Nesta plataforma foram considerados dois painéis fotovoltaicos, cujas características estão listadas na Tabela 1, ligados em série, computando assim uma potência máxima de 500W.

O painel foi dividido em 6 partes iguais, onde em cada parte era possível variar os valores de irradiância e temperatura. Variando as condições climáticas foi possível determinar os pontos de máxima potência através das curvas características PxV e IxV, como mostrado nas figura 1 e 2, para diversas situações, gerando assim uma base de dados grande o suficiente para o treinamento da Rede Neural Artificial.

Tabela 1 - Dados do painel utilizado.
\begin{tabular}{|l|c|}
\hline \multicolumn{1}{|c|}{ STC - 1000 W/m², AM 1.5, 25C } & CS6P-250M \\
\hline Potência Máxima (Pmax) & $250 \mathrm{~W}$ \\
\hline Tensão de Máxima Potência (Vmp) & $30,4 \mathrm{~V}$ \\
\hline Corrente de Máxima Potência (Imp) & $8,22 \mathrm{~A}$ \\
\hline Tensão em Circuito Aberto (Voc) & $37,5 \mathrm{~V}$ \\
\hline Corrente de Curto Circuito (Isc) & $8,74 \mathrm{~A}$ \\
\hline Número de Células & 60 \\
\hline
\end{tabular}

A base de dados montada para o treinamento da RNA foi composta pelas entradas: maior valor de irradiância dada em $\mathrm{W} / \mathrm{m}^{2}$, temperatura dada em ${ }^{\circ} \mathrm{C}$, e para identificar o sombreamento a variável utilizada foi a Tensão em Circuito Aberto dado em V. As saídas foram: Tensão de Máxima Potência dada em V, Corrente de Máxima Potência dada em A e a Potência máxima dada em $W$, extraídas a partir das curvas características de cada situação de entrada.

Variou-se a irradiância em cada parte do painel e fixouse 0 valor da temperatura. Foram coletadas as informações de Tensão de Circuito Aberto, Tensão de Máxima Potência, Corrente de Máxima Potência e Potência Máxima, para uma variação de irradiância de $200 \mathrm{~W} / \mathrm{m}^{2}$ até $1000 \mathrm{~W} / \mathrm{m}^{2}$, com intervalos definidos de $100 \mathrm{~W} / \mathrm{m}^{2}$. Uma vez que todos os dados com esses valores de irradiância foram extraídos, variou-se o valor da temperatura neste trabalho entre $15^{\circ} \mathrm{C}$ e $40^{\circ} \mathrm{C}$, com intervalos definidos de $5^{\circ} \mathrm{C}$, fazendo todas as variações de irradiância novamente e coletando os dados, gerando uma base de dados com 646 medições.
O Modelo utilizado no Matlab/Simulink $®$ para essa situação segue na figura 4, para uma das 646 medições efetuadas.

Analisando a figura 4, observa-se que é possível variar os valores de irradiância e temperatura de cada uma das seis partes no qual o painel foi dividido, gerando as curvas características de inúmeras situações.

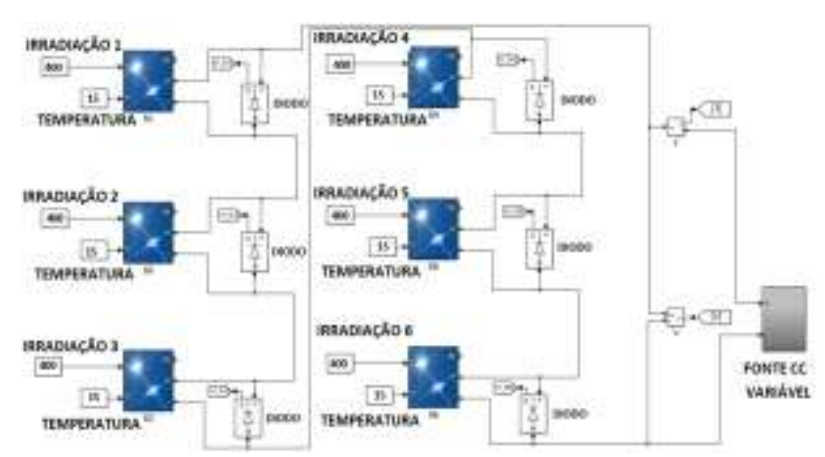

Figura 4: Modelo utilizado para geração das curvas características.

Uma vez gerada a base de dados, o próximo passo foi a configuração da Rede Neural Artificial. Como foi apresentado, a temperatura, a irradiância e o sombreamento alteram os valores de Tensão de máxima potência, de Corrente de Máxima Potência e de Potência máxima, portanto foram utilizadas como variáveis de entrada da Rede Neural Artificial.

A rede estruturada utiliza a configuração Multicamadas MLP de duas camadas ocultas, com 13 neurônios cada. O restante da rede é composta por 3 entradas e 3 saídas, como mostrado na figura 3 . Encontrar o valor da Tensão de Máxima Potência é o objetivo principal desta Rede Neural Artificial, mas notou-se que com mais dados de saída (no caso a corrente e a potência), o resultado da rede foi visivelmente melhor, por isso também foram utilizadas na etapa de treinamento da Rede Neural Artificial.

Todos os dados de entrada e saída foram normalizados com valores entre zero e um, para um melhor desempenho da rede neural. A função de ativação utilizada foi a função logística, a matriz de peso foi inicializada com valores aleatórios e o número de épocas de treinamento igual a 1000. Foram utilizadas 554 amostras para o treinamento da RNA e 92 


\section{Encontro Científico de Física Aplicada}

amostras para posteriormente realizar os testes, sendo que o método de treinamento utilizado foi 0 de Regularização Bayesiana.

\section{Resultados e Discussões}

O número de amostras utilizadas se mostrou suficiente para uma boa generalização durante o treinamento da RNA, e os resultados dos testes são apresentados na figura 5. Esta figura faz uma comparação com os valores previamente conhecidos das tensões de máxima potência e os valores provenientes do processamento da Rede Neural Artificial. É importante reforçar que os dados utilizados para o teste da Rede Neural Artificial não foram utilizados durante 0 treinamento da rede neural.

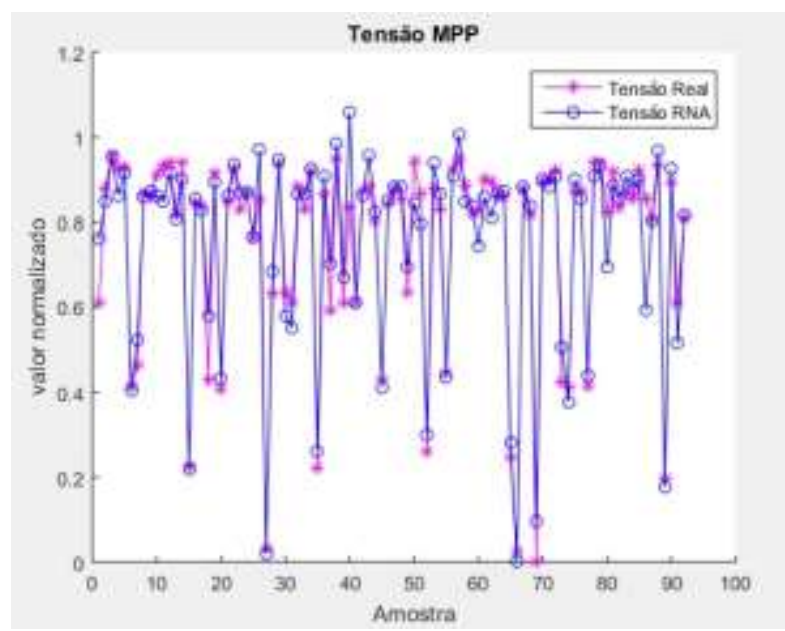

Figura 5: Comparação dos valores normalizados das tensões reais conhecidas e os valores normalizados das tensões obtidas do processamento da Rede Neural Artificial.

O erro individual de cada amostra é visualizado na figura 6. Esta figura representa a diferença entre o valor conhecido, que fora extraído a partir da curva característica do arranjo de painéis, e o valor encontrado pelo processamento da rede neural artificial. Observa-se que em apenas alguns casos 0 erros foram maiores do que $20 \%$.

O valor do erro quadrático médio foi de 0,0037, que retorna um erro médio de $6 \%$. A comparação entre a potência máxima conhecida e a potência que o sistema entregaria se a tensão utilizada como tensão de máxima potência fosse a tensão retirada do resultado do processamento da Rede Neural Artificial treinada é mostrado nas figuras 7 (gráfico de linhas) e 8 (gráfico de colunas).

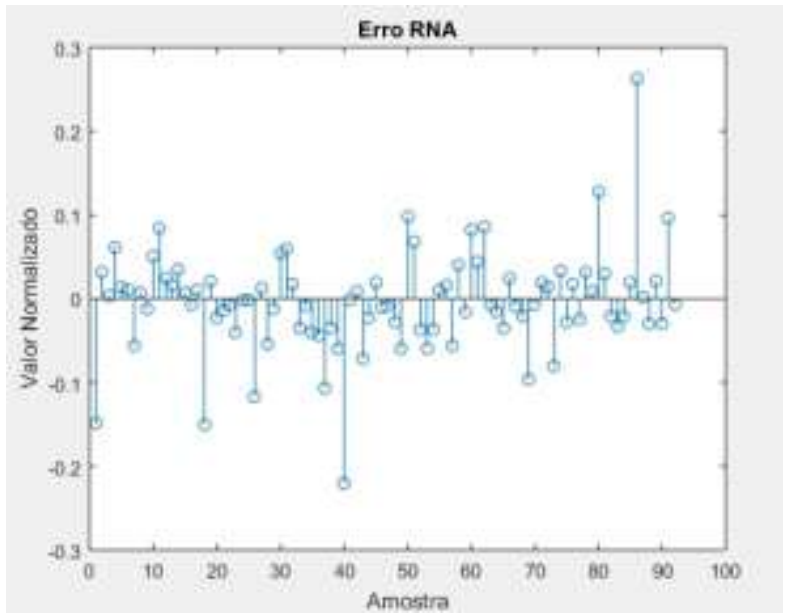

Figura 6: erro normalizado de cada amostra de teste.

É possível perceber, analisando as figura 7 e 8, que o desempenho da rede é satisfatório na maioria dos casos, fazendo com que o valor da potência entregue pelo painel (potência proveniente do valor de tensão retirado do processamento da rede neural) seja próximo do valor máximo esperado (potência máxima conhecida). Somente em alguns poucos casos houve perdas consideráveis no valor de potência, e isso acontece quando há uma variação muito grande na curva característica, ou seja, o valor do máximo global é muito próximo do valor de um mínimo local.

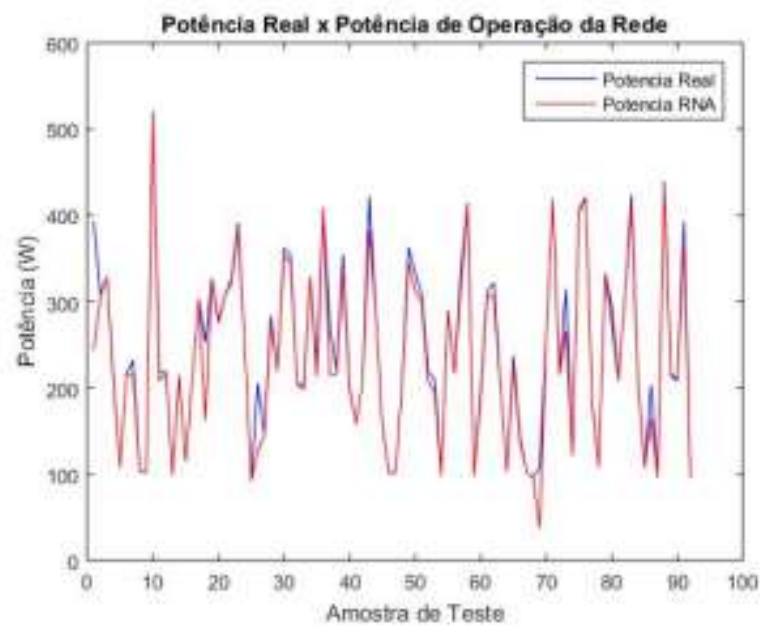

Figura 7: Comparação entre a potência máxima conhecida e a potência proveniente do valor de tensão retirado do resultado do processamento da RNA. 


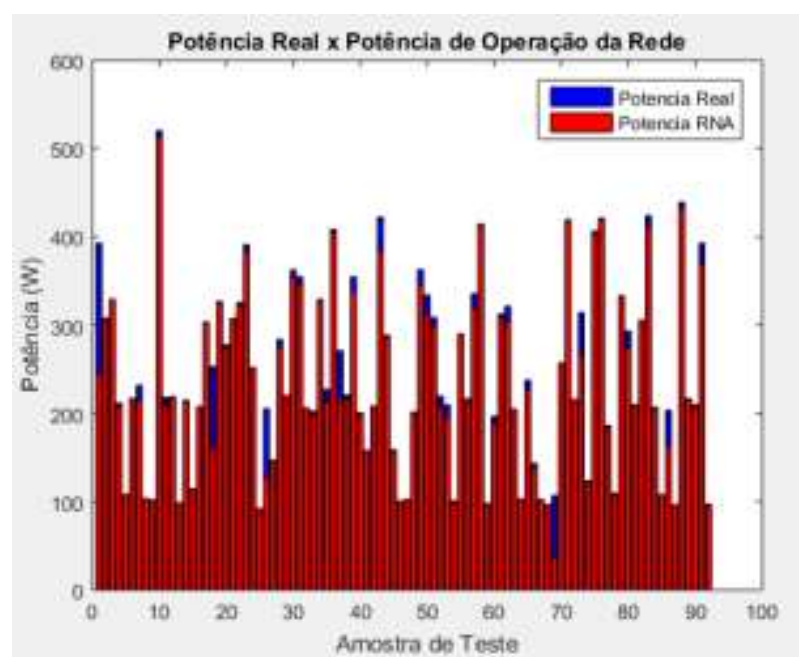

Figura 8: Comparação entre a potência máxima conhecida e a potência proveniente do valor de tensão retirado do resultado do processamento da RNA.

\section{Conclusões}

A partir dos resultados mostrados conclui-se que uma Rede Neural Artificial bem treinada, ou seja, com grande capacidade de generalização e com as considerações adequadas, pode representar a função que maximiza a potência de saída de um painel fotovoltaico. As informações empregadas para treinamento da rede se mostraram suficientes para identificar a tensão de operação com máxima potência. O erro de identificação na maioria das situações foi pequeno, podendo ser desprezado. O número de amostras da etapa de treinamento cujo erro foi maior que $20 \%$ não se apresentou significativo.

Mostrou-se, portanto, que RNA são capazes de atuar como método de rastreamento de pontos de máxima potência (MPPT) em sistemas de energia solar fotovoltaica submetida a condições de sombreamento parcial ou total. O tempo de resposta é praticamente instantâneo, com menos oscilações do que as técnicas convencionais de rastreamento de pontos de máxima potência.

\section{Agradecimentos}

Ao CNPq pelas bolsas PIBIC/UFES, e CAPES pela bolsa de mestrado.

\section{Referências}

[1] BASTOS, R. F.; MOÇAMBIQUE, N. E. M.; MACHADO, R.Q.; AGUIAR, C.R. Rede Neural Artificial aplicada na busca do ponto de máxima potência em painéis fotovoltaicos. Anais do XIX Congresso Brasileiro de Automática, CBA 2012.

[2] COELHO, D. C. Proposta de Conversor para Rastreamento da Máxima Potência de Operação de pequenos Sistemas de Geração de Energia Elétrica. 2009. 124 f. Dissertação (Mestrado) -Universidade Federal De Santa Catarina, Florianópolis, 2009. Cap. 3.

[3] DZUNG D N; BRAD L.. Modeling and simulation of solar PV arrays under changing illumination condicions. IEE COMPEL, pp 16-19, 2006.

[4] BABU, T. SUDHAKAR; RAJASEKAR, N.; SANGEETHA, K. Modified particle swarm optimization technique based maximum power point tracking for uniform and under partial shading condition. Applied Soft Computing, v. 34, p. 613-624, 2015.

[5] SILVA, I. N. Da; SPATTI, D. H.; FLAUZINO, R. A. Redes Neurais Artificiais para Engenharia e Ciências Aplicadas: Curso Prático. São Carlos: Artliber, 2010.

[6] SAMPAIO, P. T.. Modelagem Térmica de um Forno Panela Utilizando Redes Neurais Artificiais. 2006. 90 f. Dissertação (Mestrado) - Universidade Federal de Minas Gerais, Belo Horizonte, 2006. Cap. 2.

[7] MEDEIROS, T. H.. Treinamento de Redes Neurais Artificiais com Otimização Multi-Objetivo e Regularização Bayesiana: Um Estudo Comparativo. 2004. 124f. Dissertação (Mestrado) - Universidade Federal do Minas Gerais, Belo Horizonte, 2004 